\title{
El capital social como instrumento del análisis económico
}

\author{
Vicente SÁNCHEZ JIMÉNEZ \\ Doctor en Economía \\ Profesor Asociado \\ Universidad Complutense de Madrid \\ vicentes@pdi.ucm.es
}

Recibido: 21-09-2011

Aceptado: 19-10-2012

\section{RESUMEN}

Bajo la teorización del capital social se intenta analizar las vinculaciones entre economía y cultura, remarcando la trascendencia de los factores culturales como principio estructurador de la sociedad y una pieza más de la riqueza de las naciones. Entre estos factores se destaca la confianza como base de los procesos económicos modernos. A través de la conformación de esta realidad y de su inclusión en los análisis sobre el desarrollo económico y la erradicación de la pobreza, intentamos comprobar la influencia que en las últimas décadas está teniendo la visión social en la investigación económica.

Palabras clave: capital social, desarrollo económico, estructurador social.

The social capital as an instrument for the economic analysis.

\begin{abstract}
The relations between the economy and the culture is tried to be analyzed in this paper under the theorizing of the social capital, underlying the relevance of the cultural factors as the structural principle of the society and as another piece of the wealth of nations. The confidence stands out among these factors as the base of the modern economic process. An attempt of proving the influence that the social vision is having on the economic research over the last decades is carried out. This aim is tried by means of the establishment of this reality and its inclusion in the analysis of the economic development and the poverty eradication.
\end{abstract}

Key words: social capital, economic development, social structural element.

\section{REFERENCIA NORMALIZADA}

Sánchez Jiménez, V. (2013). El capital social como instrumento del análisis económico. Cuadernos de Relaciones Laborales. Vol. 31, núm. 2, p. 473-493.

SUMARIO: 1 . La necesidad del cambio en la economía. 2 El concepto de capital social. 3 El desarrollo teórico del concepto. 3.1. Bourdieu: el capital social como instrumento reproductor de la estructura social. 3.2. Coleman: el capital social como nexo entre el sujeto y la sociedad. 3.3. Putnam: el capital social como recurso comunitario. 4. Capital social y desarrollo económico. 5. Bibliografía. 


\section{La necesidad del cambio en la economía}

La configuración del sistema económico global, de la que nos hemos dotado en las últimas décadas, ha sido objeto de los más diversos puntos de vista en todos los organismos internacionales. Las teorías liberales, ante la nueva dimensión que proporciona la economía, han creído superado el análisis de los autores clásicos sobre las características que permiten el mantenimiento y crecimiento económico. El propio Smith (1776:148) lo reflejaba de la siguiente forma: "El comercio y las manufacturas no pueden florecer fácilmente en cualquier Estado que no disfrute de una administración regular de justicia, en el que la gente no se siente segura de la posesión de sus propiedades, en el que el espíritu de los contratos no es defendido por la ley, y en el que la autoridad del Estado no tiene que utilizarse regularmente para forzar al pago de las deudas de todos aquellos que son capaces de pagar. El comercio y las manufacturas, en pocas palabras, no pueden florecer fácilmente en un Estado en el que no haya un cierto grado de confianza en la justicia del gobierno".

Caso contrario de los economistas autodenominados neokeynesianos, que defienden la necesidad de diseñar de nuevo los mecanismos de control existentes ante la economía globalizada, abogando por una reorganización de las relaciones internacionales. Así, encontramos autores como Stiglitz (2006:255), quién ha puesto la voz de alarma ante la falta de mecanismos internacionales de vigilancia, en clara alusión a la diferencia que existe entre la realidad económica bajo el prisma del Estado-nación y aquella que supone la nueva evolución económica, la globalización. Esta idea se refleja en su afirmación: "Deberíamos esforzarnos en la elaboración de una legislación internacional y en la creación de tribunales de justicia internacionales, algo tan necesario para la economía global como los tribunales y las leyes estatales para las economías nacionales".

Más aún, el autor norteamericano mantiene la necesidad del sistema legal como base de las relaciones económicas y la garantía de cumplimiento de sus intercambios: "las economías de mercado comprenden una variedad de relaciones económicas, los intercambios. Muchos de esos intercambios involucran cuestiones de confianza. Una persona le presta dinero a otro y confía en que se lo devolverá. Lo que subyace a esta confianza es el sistema legal" (Stiglitz, 2009:287). Las palabras del autor norteamericano nos llevan a una reflexión aún más profunda por cuanto el cambio propuesto, además de pretender extrapolar el modelo mercado libre y Estado-nación a la esfera internacional mediante una única legislación común y sus correspondientes tribunales, pone de manifiesto la existencia de una incertidumbre mayor que la ocasionada por la economía, como así han defendido un buen número de intelectuales y científicos sociales al denominar a ésta como una "crisis de confianza".

Este hecho muestra ciertas dudas en el funcionamiento del mercado económico y, particularmente, en las decisiones que toman sus actores, lo cual ha superado a la propia economía para situarse en el campo de la estructura social. Todo ello porque ha quebrado uno de los pilares fundamentales de la sociedad, el sistema económico. Con una salvedad, las causas que han originado la incertidumbre sobre la estructura 
social, asentada en el modelo de Estado-nación, han partido de las contradicciones surgidas no del mercado nacional, como se había analizado hasta ahora, sino de las variables de la economía global. Es decir, no se han puesto en el mismo nivel de análisis ambos elementos como era habitual, pues deberíamos estar hablando de una parte de las características para el control del mercado económico por los gobiernos nacionales, a través de sus leyes y tribunales, mientras que por otra de estas mismas variables en un contexto internacional.

Ello es debido a dos motivos. Por una parte, la debilidad de los organismos internacionales para acometer el control de esta nueva etapa económica, por otra, el mantenimiento en exclusiva por parte de los gobiernos nacionales de ciertas parcelas de control en perjuicio de las instituciones supranacionales. En la práctica existe un vacío en el contrapeso a los agentes económicos privados globalizados. El supuesto autocontrol de los mercados globales, propio del pensamiento liberal, ha derivado en la falta total de reglas de juego a escala mundial. Es decir, de normas de conducta.

El pensamiento tanto de Smith como de Stiglitz, aún con la diferencia de los años, nos muestra la importancia de mantener un sistema normativo que permita el cumplimiento de lo pactado en las relaciones de intercambio, tras las cuales se asienta la confianza entre los individuos por la garantía de reciprocidad. Es decir, esta idea atemporal nos lleva al nudo gordiano de la interrelación entre tres variables: la confianza de los individuos, la legislación como garante de las relaciones de intercambio y el propio desarrollo económico. Parece oportuno mencionar que, como en el caso de los institucionalistas, los economistas han vuelto a redescubrir los vínculos entre la economía y los otros elementos sociales con el objeto de explicar las causas que caracterizan al sistema económico como un continuo modelo de autodestrucción schumpeteriana. Si bien, ante las limitaciones del análisis económico clásico y del institucionalismo afloran en la Ciencia Económica nuevas variables (sociológicas, antropológicas,...) cada vez más alejadas de estos planteamientos en el intento de profundizar aún más en descubrir los nexos entre economía y sociedad, en este caso desde el hecho cultural.

De este modo, ante la falta de respuestas de concepción exclusivamente económica frente la situación actual, volvemos la mirada hacia otras ciencias sociales, como pueden ser la Sociología o incluso la Antropología, para poder encontrar los elementos que permitan analizar más en profundidad las causas que motivan los períodos de recesión. De esta manera, no sólo se ha abierto por enésima vez el debate del papel del Estado en la economía, sino que la incertidumbre en el propio sistema ha traspasado las fronteras de la mecánica de los mercados y sus agentes, fijando su atención en los últimos años en la posible falta de ética de los altos directivos, fortalecida esta idea bajo la premisa de equiparar las decisiones tomadas con la remuneración económica aparejada.

La sociedad civil, que había creído asentado su pilar económico en un mercado liberalizado, ha enfocado sus preocupaciones hacia las decisiones tomadas por las personas que dirigen las grandes empresas multinacionales, especialmente las financieras. Volvemos, por tanto, al estudio de la persona, es decir, a la Antropolo- 
gía para encontrar respuestas ante el comportamiento individual. Retomamos, pues, el análisis de las instituciones básicas como la propiedad o la familia, encontrándonos en el camino de la antropología económica como soporte explicativo desde las sociedades primitivas, tanto en las actividades de intercambio y producción, como de los mismos fundamentos del comportamiento económico y social de los individuos en la actualidad. De hecho, se ha vuelto a poner de manifiesto que "es la forma de vida la que determina la conciencia" y, por tanto, las decisiones que han llevado a la crisis actual tienen la necesidad de encontrar respuestas en áreas de conocimiento más amplias que las simples características económicas.

El debate sobre todas estas cuestiones ha hecho que en los últimos años aparezcan textos que arrojan luz a las interconexiones entre variables tan diferentes como las psicológicas, las sociológicas y las políticas para explicar el proceso de desarrollo económico. Ello se debe a que hemos llegado al convencimiento que no podemos entender las sociedades modernas con un simple análisis unidireccional, pues si algo las diferencias de etapas anteriores es la cada vez mayor integración entre los factores culturales y económicos, como por ejemplo en el consumo de bienes y a la postre en la propia producción.

En esta línea de pensamiento encontramos autores tan recientes como Fukuyama (1995:89), quien defiende sus análisis de la competitividad en los mercados internacionales a través de términos culturales. De forma que para éste autor las relaciones económicas, las empresas y el trabajo no dejan de ser espacios en los que los individuos interactúan bajo la dinámica de la sociabilidad entre sus semejantes. De esta manera defiende estas formas de sociabilidad como una de las características culturales intrínsecas de cada país donde asentar la explicación de los resultados económicos. Así llega a afirmar que la "actividad económica se entrelaza con una gran variedad de normas, reglamentos, obligaciones morales y costumbres, que la caracterizan".

Ahora bien, Fukuyama (1992), que ya en su libro El fin de la historia y el último hombre preconiza las virtudes del sistema económica capitalista y cómo éste se ha convertido en hegemónico frente al sistema económico de los llamados países del este, da un valor extra a la confianza social como estructuradora social y del propio mercado. Este pensamiento se sitúa en línea con aquellos que vieron en el mercado la capacidad de autorregularse en contraposición al papel que el Estado había mantenido, principalmente, en los anteriores treinta años. El autor norteamericano defiende en su teoría que esta confianza social, como predisposición psicológica a la que los individuos llegan, no parte de la consecución de reglamentaciones explícitas, sino que surge de las obligaciones morales producto de las costumbres éticas de cada sociedad.

Al igual que él, otros autores, como Coleman (1988) y Putnam (1993), defienden que estas normas organizativas y de relación implícitas en los valores culturales determinan en un grado importante la capacidad para la obtención del bienestar social y el desarrollo económico. Otorgan a la confianza un valor estratégico en su teoría, pues además de darle un lugar privilegiado, entienden que una comunidad con una confianza generalizada, comprendida como condición, les capacita para formar organizaciones que maximicen las oportunidades económicas disponibles. 
Así en palabras de Fukuyama (1995:103) "el nivel de confianza inherente, como característica cultural de una nación, condiciona sus bienestar y capacidad competitiva". En otras palabras "para fomentar las virtudes individuales (como el capital humano) es imprescindible la capacidad de sociabilidad espontánea sustentada en virtudes sociales preexistentes como la honradez, la fiabilidad, la capacidad de colaboración y el sentido del deber".

Para la Ciencia Económica la peculiaridad de estos conceptos -confianza, honradez, fiabilidad- radica en la dificultad de su medición. El problema se plantea por su condición abstracta e intangible. De hecho, conceptos tan subjetivos en algunos aspectos como la calidad de vida han sido medidos en cierto número de investigaciones gracias a la configuración de instrumentos de medición específicos. Destacan, entre estos, los realizados bajo el mandato del Programa de Naciones Unidas para el Desarrollo. En su Informe de Desarrollo Humano (1999) establece un índice, medido en más de 170 países, a través de una metodología que combina la capacidad adquisitiva por medio del producto per capita, el capital humano generado y la esperanza de vida al nacer. Materias como la relación entre individuos y las instituciones, y particularmente el valor económico que esto origina no son objeto de cuantificación.

Ante el vacío en el análisis del desarrollo social y económico se ha establecido un campo de estudio propio que intenta dar respuesta a estas cuestiones. En la década pasada se populariza un concepto que pretende recoger las peculiaridades de estos elementos y estudiar la importancia que para la sociedad tienen. Antes de adentrarnos en concretar con mayor detenimiento el concepto de capital social es oportuno mencionar cuáles han sido las fuentes de las que se ha nutrido para su conformación como categoría científica. Por ello, se hace necesario indagar en aquellas ideas anteriores a las que éste debe su origen.

\section{El concepto de capital social}

El concepto de capital social parte de aquellas teorías que se preocuparon por esbozar las características democráticas y políticas latentes en toda sociedad civil, como base del mantenimiento democrático de una nación, a la vez que el desarrollo de sus ciudadanos. Autores como Aristóteles, Locke, Stuart Mill o Tocqueville, por citar algunos, alegan, desde diferentes perspectivas, una misma visión: el desarrollo de la sociedad civil permite a su vez la configuración democrática de la sociedad. Ahora bien, para el caso de las actuales teorías de la sociedad civil este hecho tiene como base la potenciación de aquellos rasgos culturales que posibilitan la creación y participación ciudadana en todo tipo de asociacionismo y organizaciones creadas desde la misma, por lo que se configuran como elementos equilibrantes a las actuaciones del Estado.

La cultura política de la ciudadanía se fortalece a través de la creación y mantenimiento de nexos de unión entre los mismos, bajo la participación activa en la vida de la sociedad, la cooperación cívica y la configuración de organizaciones. Pensa- 
miento que en esencia es recogido por todas las civilizaciones, prueba de ello son los pensadores clásicos como el ya citado Aristóteles, quien describe al "hombre" por esta cualidad como "animal político". A su vez defiende que sólo los animales y los dioses son capaces de vivir aislados, por cuanto la fuerza natural hacia la reproducción y la conservación inclina a los hombres a vivir unidos, primero en la familia, luego en la aldea, como unión de varias familias, y finalmente en la ciudadestado. El buen funcionamiento de una ciudad-estado no se asegura solamente por aunar voluntades hacia un mismo fin, se requiere también de leyes sensatas y apropiadas que respetasen las diferencias y educasen a sus ciudadanos para la responsabilidad civil dentro de la libertad.

La preocupación por encontrar el germen del que parte la solidaridad social es patrimonio de las ciencias sociales desde sus orígenes más primitivos, como hemos podido comprobar en el caso de Aristóteles. Ahora bien, como precursor de un estudio más sistemático de estas variables en la moderna estructuración de las ciencias, encontramos a finales del siglo XIX a Émile Durkheim (1993), quien mantiene la importancia de las relaciones sociales como fuente de una cooperación que permite el asentamiento de los valores de solidaridad en las sociedades modernas. Por esta vía señala que para que los ciudadanos de una misma nación compartan valores sociales y objetivos comunes es necesaria la capacidad de mantener estructuras que les permitan estrechar relaciones entre sí, proporcionando las características básicas de la sociedad en su conjunto.

La trascendencia de poseer valores comunes permite la conformación de forma generalizada de unos mismos objetivos sociales para todos los individuos, y viceversa. En este doble camino características como la cooperación y la confianza se muestran como básicas para la creación de sistemas de unión estables entre las personas.

Estos lazos de cooperación, confianza y desarrollo común de los individuos mediante la estructuración de sus relaciones fue englobado por el concepto de capital social en el estudio que Lyda Jubson Hanifan, a quien podemos considerar como el primer autor en la utilización del mismo, realiza en 1916 sobre la mejora de las escuelas comunitarias rurales en Virginia Occidental, con el objeto de poder explicar los nexos entre el compromiso comunitario y el desarrollo económico. En este ensayo llegó a la conclusión que la situación de exclusión y pobreza en la que se encontraban los ciudadanos de dichas poblaciones era consecuencia del importante déficit de lo que el denominó capital social, cuya primera definición se extrae de la explicación siguiente: “...esos elementos tangibles cuentan sumamente en la vida diaria de las personas, a saber, la buena voluntad, la camaradería, la comprensión y el trato social entre individuos y familias, características constitutivas de la unidad social (...) Abandonado a sí mismo, el individuo es socialmente un ser indefenso (...) pero si entra en contacto con sus vecinos, y éstos con nuevos vecinos, se producirá una acumulación de capital social que podrá satisfacer de inmediato sus necesidades sociales y producir unas posibilidades sociales suficientes para mejorar de forma sustancial las condiciones de vida de toda la comunidad". 
Podemos corroborar que lo que el autor estadounidense expresa es la convicción de otorgar a las redes sociales y a las normas morales recíprocas ligadas a éstas la mejora del bienestar socioeconómico de la comunidad, evitando a su vez el aislamiento familiar e individual. Por tanto, defiende la importancia manifiesta de que los miembros de una comunidad tengan la capacidad de crear vínculos sociales estables en el tiempo.

Con posterioridad, autores como Glenn Loury (1977) o Mark Granovetter (1973) realizan trabajos en torno a este fenómeno, y aún no habiendo desarrollado el concepto se convierten en importantes referentes del tema.

En el caso de Granovetter (1973:48), su acercamiento al capital social se realiza a partir de su estudio La fuerza de los vínculos débiles sobre la movilidad ocupacional y las formas por las cuales los trabajadores acceden a nuevos empleos. Una de las conclusiones a las que llega es que los vínculos no primarios poseen una mayor relevancia de la que hasta esos momentos había sido objeto de atención, idea que se refleja en sus palabras "una idea natural a priori es que aquellos con quienes se tienen vínculos fuertes están más motivados para ayudar sobre información acerca de trabajo. Contrarios a esta gran motivación están los argumentos estructurales que he estado realizando: aquellos con quienes estamos débilmente vinculados son más propensos a moverse en círculos distintos al propio y, por tanto, tendrán acceso a una información diferente a la que nosotros recibimos".

Pero si existen autores gracias a los cuales el concepto de capital social es ampliamente utilizado en las ciencias sociales desde los años noventa, constituyendo uno de los elementos innovadores de la teoría social contemporánea, debemos hacer mención a la triada compuesta por Bourdieu, Coleman y Putnam, quienes se han convertido por meritos propios en las referencias más frecuentes. A ellos dedicamos el siguiente epígrafe por constituir las tres perspectivas centrales de las que han partido los desarrollos empíricos y conceptuales del capital social. Pensamos que a través de ellas también se pueden enmarcar, con un mejor soporte analítico, las virtudes y problemas que acompañan al concepto.

\section{El desarrollo teórico del concepto}

\subsection{Bourdieu: el capital social como instrumento reproductor de la estruc- tura social}

Como hemos comentado, a pesar de los importantes aportes teóricos de autores como Hanifan y Granovetter, en líneas generales se considera a Pierre Bourdieu como el primer autor que se adentra en el estudio sistemático del capital social.

Para entender el desarrollo teórico del autor francés acerca del capital social se hace necesario analizar previamente otro término destacado de su contribución teórica, el habitus. La formulación sistemática y sociológica de este concepto supone una de sus aportaciones más destacadas a la Sociología, pues aunque previamente ya estuviese presente en la obras de algunos sociólogos clásicos, como es 
el caso de Max Weber (2003), su introducción se produce sin un desarrollo teórico, ni siquiera llegar a definirlo.

Pierre Bourdieu (1992:88) entiende habitus como "historia incorporada, hecha naturaleza, y por ello olvidada en cuanto tal, el habitus es la presencia actuante de todo el pasado del que es el producto: de partida, es el que confiere a las prácticas su independencia relativa en relación a las determinaciones exteriores del presente inmediato". Es decir, en palabras del propio autor de forma más concreta: "los condicionantes asociados a una clase particular de condiciones de existencia producen habitus". Por ello, el habitus tiene su razón de ser como estructura social interiorizada en la medida que se incorpora al individuo en forma de esquemas de percepción y pensamiento, constituyéndose como la forma más estable para preservar las acciones, por encima incluso de las normas formales y explícitas exteriores.

El habitus será, por tanto, lo que nos permita explicar por qué las actuaciones de los sujetos no pueden entenderse con el análisis unilateral de su posición actual en la estructura social, sino que estas prácticas serán causadas en base al proceso de "socialización primaria", por cuanto constituye la repetición de los esquemas generativos en los que se hayan recogidos las divisiones del mundo social. Bordieu establece por esta vía una visión relacional e histórica para poder explicar la simbiosis social de estas estructuras, acercándose al concepto de capital social desde una posición instrumentalista.

El acercamiento que el sociólogo francés realiza hacia el concepto de capital social gira en torno a los posibles beneficios que se pretenden obtener por parte de los sujetos de la configuración de dicho capital en base a relaciones sociales. De este modo define el capital social como "el agregado de los recursos reales o potenciales que se vinculan con la posesión de una red duradera de relaciones más o menos institucionalizadas de conocimiento o reconocimiento mutuo" (Bourdieu, 1985:248). En base a esta percepción de la configuración del capital social como fuente de beneficios, es donde el autor francés sustenta que dicho concepto se establece como mecanismo por el cual los sujetos son capaces de acceder a otros tipos de capital, reduciendo en último término el interés por la creación de capital social como forma de garantizar el capital económico. El capital social en forma de asociaciones y redes sociales viene a facilitar al individuo el acceso a los recursos del resto de integrantes de la misma red, "de allí que, a través del capital social, los actores puedan obtener acceso directo a recursos económicos (prestamos subsidiarios, información sobre inversiones, mercados protegidos); pueden incrementar su capital cultural gracias a los contactos con expertos o individuos refinados, o de manera alternativa, asociarse a instituciones que otorgan credenciales valoradas" (Portes, 1999:248).

En Bourdieu, de la misma forma que en Coleman y Putnam, las redes sociales y la densidad de las mismas, en función de asociación de los individuos, se estructuran como motor de la creación y durabilidad del capital social y, por tanto, en la fuente principal de garantía ante las expectativas de reciprocidad. En el caso de Pierre Bourdieu esta idea se basa en las diferencias que observa entre los intercambios propiamente económicos y aquellos que surgen directamente del capital social, las 
cuales engloba en dos: el mayor grado de trasparencia de los primeros y la mayor incertidumbre de los segundo.

\subsection{Coleman: el capital social como nexo entre el sujeto y la sociedad}

Aún teniendo la obra de James Coleman una extensa proliferación de ideas en torno a la teoría del capital social, podemos mencionar dos elementos trasversales a todo su desarrollo teórico sobre este concepto. El primero, la postura de que la acción social está estructurada a través de interacciones. Estas interacciones se conforman como estructura para los sujetos que participan de ella, de tal forma que a través de esta interacción se conforman vínculos, por lo que será la propia estructura de esta interacción la que englobe elementos que conformen el capital social, según sus funciones de cooperación y coordinación. La estabilidad y permanencia de las interacciones vendrá de la mano de los contextos institucionales que engloban las acciones de los participantes, regulándolos. El segundo, de acuerdo a lo anterior, las relaciones sociales fomentan la interdependencia de los actores, constituyéndose el capital social.

Para Coleman el capital social se constituye como un mecanismo cuya particularidad estriba en que es algo inherente a la estructura de las relaciones sociales. Este mecanismo se orienta a la consecución de los objetivos del propio sujeto, que de otra forma serían imposibles de conseguir o cuyo costo sería excesivo para poderlos obtener. Coleman (1990:301) llega a definir el capital social como función, siendo "el valor de esos aspectos de la estructura social que los actores pueden usar como recursos para la realización de sus intereses". Dicho de otra forma, el capital social se establece como base de la estructuración social al facilitar ciertas acciones de los actores dentro de dicho ámbito. Del pensamiento de este autor podemos extraer que el capital social se crea a raíz de las relaciones que se establecen entre sujetos para lograr un objeto común. Como consecuencia encontramos un proceso de conformación del capital social tan amplio que permite su formación en multitud de contextos sociales, además de asumir las formas más variadas.

Ante esta amplitud del concepto, Coleman puede englobar un sinfín de relaciones sociales como originarias de capital social. Entre ellas cita la utilización de amigos y conocidos como fuentes de información; las relaciones de autoridad; las organizaciones sociales; el establecimiento de obligaciones y expectativas; y, el desarrollo de sistemas de normas y sanciones dentro de una comunidad. Las dos últimas serán las que ocupen un lugar central en su teoría y a las que dedicaremos nuestro particular análisis.

El establecimiento de obligaciones y expectativas es una de las relaciones sociales más desarrolladas por el autor inglés. Ello se puede entender si tenemos presente la crítica que él plantea a la corriente económica clásica y neoclásica, pues en contra de los planteamientos de ambas Coleman (1990:302) defiende que las sociedades actuales se caracterizan por evolucionar hacia mayores grados de interdependencia y no de individualismo, lo cual se debe a que los intereses particulares dependen en la mayor parte de los casos de condiciones o controles de otros actores, "pues los 
individuos no actúan independientemente, los objetivos no son alcanzados independientemente, y los intereses no son completamente egoístas".

El binomio entre el compromiso y la confianza de recompensa se origina en el intercambio de favores entre personas que se encuentran en una misma estructura social. Desde el momento en que un sujeto realiza una acción con la convicción de que el beneficiario de la misma se comporte de manera recíproca en el futuro, se está originando el capital social, por cuanto se establece entre ambos individuos una interacción de acuerdo a expectativas y obligaciones. La expectativa a la obtención de la reciprocidad de aquel que otorgó el beneficio de la acción, y la obligación de no dañar la confianza depositada por parte del receptor del favor.

Junto a estas dos características, expectativas y obligaciones, Coleman define como elemento fundamental del capital social su carácter interno a la estructura de las relaciones sociales. A ello añade la necesidad de ciertos factores sociales como el grado de confiabilidad del entorno social, las necesidades de las personas y el grado de densidad de las redes sociales para la conformación de esta forma de capital social.

Otra de las formas de capital social a la que Coleman dedica mayor interés es al establecimiento de normas y sanciones dentro de una comunidad. Ello se basa en el convencimiento social de demarcar las acciones que han de ser promovidas y aquellas que deben ser prohibidas mediante mecanismos reguladores de la conducta. Nos introducimos, pues, en la dimensión ética de las acciones personales a través de los valores, comportamientos y acciones que deben ser objeto de recompensa o sanción, con la finalidad de conseguir como resultado la internalización de dicho sistema de valores y sanciones por parte de los individuos de la estructura.

Este posicionamiento lleva aparejado el resultado positivo desde la perspectiva social de la acción individual, en la medida que la implementación de las normas entre los miembros de una misma comunidad ofrece resultados beneficiosos no sólo para el sujeto sino para sus semejantes. Reflejo de lo cual son las palabras de este autor: "las normas efectivas que inhiben el delito hacen posible caminar libremente de noche por la ciudad y permiten que los ancianos dejen sus casas sin temor por la seguridad". (Coleman, 1990:307)

Es aquí donde encontramos más similitud en el pensamiento de Coleman y Bourdieu, en particular la importancia que ambos autores otorgan a las redes sociales para posibilitar el surgimiento de capital social, especialmente de las dos formas descritas por el autor inglés. Coleman refuerza esta condición mediante la propia densidad de las redes sociales, y ello es debido a que condiciona a la existencia de interdependencia suficiente como para garantizar tanto el establecimiento de obligaciones y expectativas de reciprocidad como la creación y desarrollo de sistemas de normas y sanciones.

Parece, por tanto, lógico que la teoría social de Coleman defienda que cuanto mayor son los lazos de unión e interconexión entre los actores sociales es más factible el control de los comportamientos individuales que no respetan las expectativas creadas, minorando las pérdidas de confianza y reciprocidad de los intercambios, a la vez que se fortalecen ambas variables. En palabras del autor inglés: "lo 
cercano de la estructura social es importante, no solo por la existencia de normas efectivas, sino también por otra forma de capital social: la confiabilidad de las estructuras sociales que permiten la proliferación de obligaciones y expectativas. Escapar de una obligación es una forma de imponer una externalidad negativa en el otro. Sin embargo, en una estructura sin cercanía, puede ser sancionado (si puede), sólo por la persona a la que la obligación es debida". (Coleman, 1988:105).

Esta proximidad de las redes sociales parte de dos premisas. La primera es la cercanía física de las mismas como potenciador de las interacciones de forma frecuente entre los individuos inmersos en ellas. La segunda se vincula al establecimiento de obligaciones entre los sujetos de una misma comunidad, por cuanto nos lleva a la concreción de normas y sanciones que garanticen el cumplimiento de las expectativas y el reforzamiento de las relaciones de confianza y reciprocidad.

Ahondando en esta idea, los siguientes problemas a lo que se enfrentó Coleman fueron, por una parte, identificar cuál es el objeto de intercambio, pues la premisa que estos tipos de capital social se basan en relaciones de intercambios. Por otra, encontrar las características que dan estabilidad y permanencia a estas relaciones. Dicho de otra forma, descubrir la relación entre la acción individual y el intercambio social.

El objeto de intercambio según Coleman vendría referido por la permuta de bienes privados, más en concreto, el derecho de control sobre ciertas acciones. Claro que, como parece lógico, defiende que sólo puede ceder derechos quien previamente los posee, es decir, deben haber sido creados, institucionalizados y legitimados en un proceso social.

Desde esta perspectiva, Coleman (1990:310) es capaz de tomar el concepto de acción racional de la teoría económica y ampliarlo al ámbito de lo social a través de las interacciones de intercambio. Ello nos conduce de nuevo a la visión funcional del capital social que realiza este autor y la definición que del mismo apuntábamos al principio. Pero a diferencia de la visión economicista del capital financiero o el físico, el capital social no sólo beneficia a quien invierte directamente sino que todos aquellos que participan de las mismas redes disfrutan de sus beneficios de forma indirecta, es decir el capital social no es "la propiedad privada de ninguna de las personas que se benefician de él", sino un atributo de la estructura social, entendida como red social, en la que los individuos están insertos.

A modo de resumen diremos que para Coleman los principales recursos que componen el capital social y cuyo desarrollo impacta sobre el grado de cohesión social y bienestar socioeconómico, en términos de beneficios mutuos de una sociedad, serían cuatro: las redes sociales, constituidas a su vez por lazos de parentesco; las redes comunitarias informales y las organizaciones sociales; las normas de contenido voluntario cívico y altruista; y, los vínculos de confianza social. Igualmente, queremos reflejar que en su concepción de capital social encontramos cuatro indicadores básicos: se ubica entre individuos; facilita la cooperación, principalmente cuando las interacciones se encuentran dentro de un marco reglamentado; genera beneficios, en la medida que supone un mecanismo adecuado para la consecución de objetivos; $y$, en consecuencia, posee un dimensión privada y otra pública. 
De la misma forma que comprobamos como para Coleman la base del capital social radica en las normas comunes que producen beneficios externos, más en concreto, beneficios individuales, veremos que para Putnam, la respuesta se encuentra en el elemento cívico de las relaciones y en los factores que lo favorecen, éstos son la confianza y las redes. En contraposición a estas diferencias, encontramos que la idea del capital social como bien público es la que acerca de forma más clara el pensamiento de ambos, como más tarde tendremos oportunidad de analizar.

\subsection{Putnam: el capital social como recurso comunitario}

Robert Putnam en su obra de 1993, Making Democracy Work: Civic Traditions in Modern Italy, destaca la importancia de crear organizaciones horizontales en una sociedad para la conformación del capital social, al considerarlas instrumentos imprescindibles para logra el bienestar social. Esta defensa la basa en suponer que dichas estructuras posibilitan una participación más activa de los sujetos a través de actividades comunes sujetas por comportamientos recíprocos de solidaridad, lo cual a su vez enriquece la confianza social.

Su teoría está fundamentada en la observación y el posterior análisis realizado en comunidades del sur de Italia. Defiende que los sujetos de estas sociedades basan sus relaciones sociales a través del vínculo de la familia, lo que produce una fuerte presencia de desconfianza social. De esta forma, el autor norteamericano interpreta que el grado de desarrollo claramente deficitario, tanto en su versión económica, como en los procesos tecnológicos e incluso en el propio proceso de democratización o desarrollo democrático-institucional de la comunidad, se debía a las dos características anteriormente mencionadas: confianza y redes.

La integración plena de los ciudadanos en la sociedad es insuficiente debido a que estos siguen sujetos a una estructura familiar que impide una colaboración más activa entre individuos. La familia y el Estado forman los dos únicos vínculos sociales entre los ciudadanos, convirtiéndose en sus referentes cognitivos y conductuales. Por ello, los individuos son incapaces de crear otro tipo de asociaciones al margen de ambas estructuras sociales, limitados, a su vez, para diseñar actuaciones comunes sobre la base del bien social en contraposición al dirigismo oportunista que aún prevalece.

Putnam a través del análisis de las causas del estado de pobreza, corrupción y vulnerabilidad de estas comunidades, como medio para comprender los problemas que representa la acción colectiva, diseña su teoría sobre el capital social. Para él representa el activo proveniente por acumulación histórica de la acción colectiva organizada entre miembros de una comunidad, en torno a normas sociales de cooperación, valores compartidos y amplio tejido social.

De ahí que defienda que una red vertical, por muy influyente que sea para los sujetos que participan en ella, no está asentada en los principios de confianza y cooperación, como sí lo hacen las redes horizontales. Ello es debido, entre otros motivos, a que los flujos de información horizontales son más confiables que los 
verticales. Dicha cooperación está basada en el compromiso cívico, que es el factor fundamental para poder desarrollar los procesos democratizadores sociales.

En su obra utiliza el capital social como una característica propia de cada sociedad, minimizando su importancia como recurso de carácter individual. Así, desde este nuevo punto de vista, define el capital social como "aspectos de la organización social tales como la confianza, normas y redes, que pueden mejorar la eficiencia de una sociedad al facilitar la acción coordinada" (Putnam, 1993:167).

A través de esta visión particular realiza una aproximación a contextos macrosociales, señalando que el grado de confianza, la reciprocidad, las redes sociales y, particularmente, el compromiso cívico, explican que una comunidad haya alcanzado un desarrollo económico y democrático mayor que otras. Ello, además, porque considera que la existencia de todas estas dimensiones tiende al reforzamiento mutuo de las mismas, produciendo así equilibrios sociales con altos niveles de cooperación. Putnam asienta en estos elementos su teoría del capital social. Pasamos a desarrollarlos.

El autor norteamericano define la confianza como un componente del capital social por cuento estima que "la confianza lubrica la cooperación. Cuanto mayor es el grado de confianza dentro de una comunidad, mayor la probabilidad de cooperación. Y la cooperación, a su vez, refuerza la confianza". Al igual que Coleman (1990), Putnam (1993:167) asienta la confianza entre sujetos en la capacidad de percibir las actuaciones futuras de los demás, así recoge que "uno no confía que una persona hará algo simplemente porque dice que lo va a hacer. Uno confía sólo porque, conociendo la disposición del otro, sus opciones disponibles y sus consecuencias, su capacidad, etc., uno espera que él elegirá hacerlo". Pero para que la confianza personal llegue a conformar una confianza generalizada en la comunidad, confianza social, es necesario la estructuración de redes sociales y el desarrollo de normas de reciprocidad entre sujetos. Cuanto mayor sea el grado de las mismas y su intervención mayores grados de confianza social se generarán. Ello nos lleva al segundo de los elementos básicos propuestos que conforman el capital social según la teoría de Putnam, la reciprocidad generalizada.

La reciprocidad generalizada, basada en la devolución futura de una actuación beneficiosa en el presente, fortalece la confianza entre las partes a través de la exclusión de las conductas oportunistas y el aumento de las garantías de cumplimiento de las expectativas de retorno. Dicho con sus propias palabras: "de este modo, sus reputaciones están en juego, las que son, seguramente, más valiosas que las ventajas de traiciones momentáneas. En ese sentido, la honestidad es estimulada por la existencia de redes sociales densas" (Putnam, 2000:136). Estas redes sociales densas que menciona Putnam permiten un mantenimiento de las condiciones en el tiempo, lo que posibilita, a su vez, nuevas oportunidades de relaciones. Cuanto mayor es la densidad de las redes mayor es la reducción de oportunismo en las comunidades, pues también es mayor el grado de eficacia de sistemas de normas y sanciones.

Como ya hemos mencionado, en el pensamiento del profesor de Harvard las redes pueden ser de dos tipos, horizontales y verticales. Las redes horizontales "reúnen agentes de status y poder equivalentes". Las verticales "vinculan agentes de- 
siguales en relaciones asimétricas de jerarquía y dependencia" (Putnam, 1993:171). El autor destaca las relaciones entre iguales como verdaderas potenciadoras de capital social. Así, mientras las redes horizontales son definidas como redes de compromiso cívico, las redes verticales se caracterizan por la subordinación implícita en la jerarquía.

Las asociaciones de vecinos, las asociaciones culturales, las cooperativas y los clubes deportivos son claros ejemplos de redes sociales horizontales y responden a una interacción social intensa. Este tipo de redes de compromiso cívico "constituyen una forma esencial de capital social: cuanto más densas las redes de una comunidad, más probable es que los ciudadanos estén dispuestos a cooperar para el beneficio mutuo" (Putnam, 1993:171). Ello genera efectos tanto en el interior de la propia asociación, como pueden ser la cooperación y la solidaridad entre sus miembros, como en su ámbito externo concretando intereses comunes entre sus miembros y orientando su actividad en el propósito de conseguirlos. Llegamos así a la cuarta dimensión en las que Putnam asienta su modelo teórico de capital social: el compromiso cívico.

El compromiso cívico es entendido como el nivel de implicación activa de los ciudadanos en los asuntos públicos de la comunidad. El autor norteamericano intenta cuantificar esta idea mediante la cantidad de asociaciones y el nivel de participación de los sujetos en las mismas. De aquí se sustrae que Putnam defienda que la densidad de las redes de asociaciones civiles y el activo compromiso en los asuntos comunitarios influyen en los niveles de exigencia hacia los gobiernos, por cuanto los sujetos están coordinados a través de la actuación colectiva para conseguir unos fines comunes de responsabilidad social.

Aunque es cierto que Bourdieu, Coleman y Putnam son los autores de referencia cuando se habla de capital social, ya que fueron los que concretaron el concepto y lo sistematizaron teóricamente, debemos tener en cuenta que existe un buen número de autores que han profundizado en los últimos años su desarrollo, fruto del cual se han suscitado críticas y nuevas interpretaciones sobre la dimensión y concreción del concepto.

\section{Capital Social y Desarrollo Económico}

El capital social se configura para la Ciencia Económica como una analogía al término capital económico dentro de las teorías del desarrollo económico surgidas en la década de los años 60 del siglo pasado, particularmente de los modelos de economías alternativos. En concreto se ha utilizado como respuesta a los fracasos de la idea economicista del desarrollo. La propuesta al recurrir a este concepto es la de incluir valores como la confianza entre los sujetos, la capacidad asociativa, la cooperación, la conciencia cívica y la ética de la sociedad y, por tanto, volver a jerarquizar los análisis dirigidos a la erradicación de la pobreza. De esta forma se orienta el análisis a una percepción mucho más amplia que los simples resultados numéricos de bienes y servicios o de necesidades materiales, consiguiendo con ello una visión más rica y completa para la elaboración de actuaciones gubernamentales 
o de organismos internacionales, en la línea de conseguir estrategias de desarrollo económico y social participativo, equitativo y sostenido por los propios actores en el tiempo.

La perspectiva del capital social para evaluar problemas de pobreza es holística. Junto con la capacidad de determinar las deficiencias de bienes básicos y servicios elementales, se tiene en cuenta la falta de aspectos socio-emocionales de la población. Así, mediante el análisis de las redes sociales de estas comunidades en situación extrema, se pretende indicar la vulnerabilidad existente para afrontar la salida a una situación de necesidad material.

El acercamiento al capital social desde la perspectiva económica hace que se supere la concepción del modelo clásico sobre los motivos que orientan a las personas en su actividad económica, esto es: la simple obtención de beneficios materiales y financieros. En este sentido plantea que lo niveles de intercambio sirven, además de para satisfacer nuestro deseo por bienes y servicios tangibles, para lograr bienes socio-emocionales, presentes en todas las relaciones de intercambio.

Este enfoque va en contra del pensamiento clásico y neoclásico, pues ambos conciben las interrelaciones sociales como la suma de las actuaciones individuales para la consecución de objetivos particulares, lo que da origen a la competencia de mercado. En cambio, la perspectiva del pensamiento económico actual se dirige al análisis de las estructuras sociales que los individuos crean para lograr unos objetivos comunes a través de una cooperación mutua como única forma de conseguirlos, como defiende, entre otros Coleman.

Percepción que cambia más profundamente en la obra de Putnam (2000), como hemos visto. En ella proporciona el embrión conceptual y metodológico para comprender y cuantificar el desarrollo de una sociedad civil, partiendo del concepto de capital social. De esta forma Putnam defiende que la riqueza y fortaleza del tejido social provoca efectos evidentes en la estabilidad política y económica, la calidad del gobierno, y otras áreas tales como la sanidad y el urbanismo.

Desde la perspectiva del desarrollo económico, el capital social se constituye como el conjunto de normas, redes sociales y organizaciones construidas sobre relaciones de confianza y reciprocidad, que contribuyen a la cohesión, el desarrollo y el bienestar de la sociedad, así como a la capacidad de sus miembros para actuar y satisfacer sus necesidades de forma coordinada.

Esta posición parte de la idea que el capital social no sólo supone un intento para medir la colaboración social entre los diversos grupos de un colectivo humano, además es interpretado como el instrumento de acceso del individuo ante las oportunidades que se crean a partir de esta cooperación. Dicho de otra forma, los individuos satisfacen sus deseos y necesidades de manera más fácil cuando se potencia en su sociedad la confianza mutua, las redes sociales y unas normas efectivas, tres características que todos los autores confieren para la existencia de un capital social positivo.

Para la Ciencia Económica el capital social es el instrumento con el que se mide la sociabilidad de los conjuntos humanos. Le otorga importancia como potenciador de la colaboración a través de proyectos conjuntos, es decir, mediante la implantación de la acción colectiva. A ello le une su papel como medidor del beneficio que cada individuo obtiene de las oportunidades surgidas por estas relaciones sociales. 
Es a partir de mediados de la década pasada cuando empiezan a surgir las primeras manifestaciones del término de capital social en los organismos económicos internacionales. La institucionalización del concepto en la teorización y desarrollo en la economía política mundial vino de la mano del Banco Mundial, al constituir en 1994 en el seno de su Unidad de Desarrollo Social el grupo de trabajo sobre capital social. Este acto supone una ruptura con las teorías del pensamiento clásico y neoclásico, al defender abiertamente la necesidad de tomarlo como referencia por los análisis económicos, particularmente por aquellos economistas vinculados al desarrollo, variables institucionales, políticas y sociológicas.

Sólo tres años más tarde el Banco Mundial (1997a), en el informe anual que dedica al desarrollo económico, alerta que para que éste se pueda considerar satisfactorio debe existir un desarrollo social paralelo. Se estima que aquellas naciones que poseen reservas suficientes de capital social tienen mayores recursos para luchar contra la pobreza y la vulnerabilidad de sus ciudadanos, además de lograr un desarrollo humano y económico más sostenible; por otro lado, contarán con instrumentos de descentralización del poder de los gobiernos ejecutores, pues la sociedad civil dispondrá de mayores mecanismos para acceder a información, facilitar su coordinación y la toma colectiva de decisiones.

La pobreza ya no es estudiada por los organismos internacionales como la escasez de bienes físicos y servicios básicos, sino que a estos debemos añadir la negación de bienes socio-emocionales. El Banco Mundial (1997b) enfatiza en que los pobres son resultado de la suma entre la falta de bienes y servicios materiales y el acceso limitado a bienes socio-emocionales, como son el respeto, el aprecio y la participación e inclusión social. El capital social, según este organismo, en la medida que permite eliminar las barreras de vulnerabilidad de individuos y sociedad favorece la lucha simultánea contra la pobreza y la exclusión social de forma más eficaz. Además, a través de la creación de redes, también posibilita la estructuración de la sociedad civil, resultado de lo cual encontramos sistemas de gestión pública más eficientes, pero sobretodo más trasparentes.

En un nuevo paso por introducir más variables de estudio al pensamiento económico, dicho de otro modo, con el objeto de lograr una mayor fiabilidad de las teorías ante una realidad que es manifiestamente compleja y volátil, el Banco Mundial (1998) publica su escrito Las instituciones cuentan. Como si se tratase de retomar el trabajo de los institucionalistas, este organismo define las instituciones como el conjunto de reglas formales e informales y sus mecanismos de ejecución que inciden sobre el comportamiento de los individuos y las organizaciones de una sociedad. En este caso particular se delimitan las instituciones a la forma de actuar. Así, podemos entender que las reglas formales son aquellas compuestas por constituciones, leyes, regulaciones y contratos, mientras que las reglas informales se refieren a la ética, la confianza, los preceptos religiosos y los códigos de conducta implícitos.

Con estos planteamientos el Banco Mundial orienta su análisis económico hacia una visión más amplia de la sociedad, por cuanto para entender ciertos resultados económicos es necesario comprender también qué cambios institucionales y estructurales han formado parte del efecto, ya que si estos condicionantes o factores no se 
tuvieran en cuenta, en ciertos momentos históricos y en determinados países, no se podría generar la estabilidad política necesaria para asegurar la estabilidad financiera, base esencial para un posible crecimiento sostenido. Es decir, el análisis del tejido social básico de una región, junto con el fomento de su capital social y humano, se convierten en caminos fundamentales de obtención de productividad, progreso tecnológico y competitividad de un país en los escenarios económicos mundiales. Todo ello da la razón a autores que décadas anteriores promulgaban la interdependencia de la Economía con el resto de áreas sociales, como es el caso de Ward (1973:252), que a principios de los años 70 del siglo pasado afirmaba que "aún no ha desaparecido el aislamiento con respecto a otras disciplinas que caracterizó a la economía en el pasado, pero ciertamente está a punto de desaparecer".

De la misma manera no puede extrañar que el Banco Mundial haya llegado a considerar el capital social como una forma de capital. Junto a él se encuentran: el capital natural, constituido por la dotación de recursos naturales de un país; el capital construido, generado por el ser humano y que incluye otras subformas de capital, como infraestructuras, bienes de capital, capital financiero, capital comercial, tecnología; y el capital humano y el conocimiento.

Igualmente, este organismo internacional llega a afirmar a través de sus proyectos que la lucha para reducir la situación de vulnerabilidad de los individuos y sus familias pasa por la vertebración de las comunidades mediante la conformación de redes sociales. De esta forma puede entenderse que una de sus recomendaciones sea que los gobiernos nacionales apoyen a las organizaciones no gubernamentales con el objeto de promocionar formas deseables de capital social.

A esta forma de interpretar la realidad actual por parte del Banco Mundial se han incorporado otras instituciones internacionales. La Organización para la Educación, la Ciencia y la Cultura de Naciones Unidas, UNESCO (1996:14), en su Informe de la Comisión Mundial de Cultura y Desarrollo afirma que "la cultura son maneras de vivir juntos..., moldean nuestro pensamiento, nuestra imagen y nuestro comportamiento". La UNESCO considera el factor cultural como pilar básico del capital humano y del social, ya que al incidir marcadamente sobre el estilo de vida de los diversos grupos sociales se convierte en cuestión de extraordinaria importancia en la generación de riqueza entre los ciudadanos de un país.

Este cambio de orientación en la elección de los instrumentos de análisis social y económico se plantea como un componente superador de elección más limitado. A su vez se le da valor a variables que no habían contado de forma tan decisiva en los programas económicos de instituciones internacionales como las mencionadas, el Banco Mundial y la UNESCO.

En la actualidad se considera necesario complementar los tradicionales análisis del capital humano y físico, tanto de la cuantificación de conocimientos y bienes materiales, con otros elementos condicionantes del bienestar social y económico. De ahí la inclusión del capital social como un factor más de productividad individual y colectiva en los estudios de las organizaciones y agencias de cooperación internacional. Los trabajos de Putnam y estudios similares han contribuido a extraer el valor diferencial entre las sociedades con elevadas reservas de capital social 
frente a aquellas que no lo poseen. Las sociedades con mayores niveles de capital social dispondrían de sujetos con más instrumentos para conseguir la satisfacción de sus necesidades individuales y de mejores mecanismos para llegar a cubrir los objetivos colectivos, como bien público, ya que potencia la democratización social, el civismo, reduciendo las ocasiones de oportunismo y, por tanto, teniendo índices más bajos de economía sumergida. No olvidemos que Making Democracy Work: Civic Traditions in Modern Italy se publicó en 1993 y, casualmente, es a partir de entonces cuando instituciones de todo el mundo incluyen la variable del capital social dentro de sus análisis y publicaciones.

El problema del capital social para el pensamiento económico reside en el escaso desarrollo del término fuera de las teorías propias de su concepción y en la reciente introducción en el marco de la Ciencia Económica. Al existir una enorme dificultad para su cuantificación, se constituye en la actualidad como un instrumento complementario a realidades más tangibles y estudiadas como son el capital humano y el capital físico. Lo que está claro es que no existe un acuerdo entre los investigadores sobre qué modos particulares aporta al desarrollo, en cómo puede ser generado y utilizado, y cómo puede ser articulado y estudiado empíricamente. Aún así, su utilización resulta cada vez más extendida para analizar la satisfacción de necesidades individuales y el desarrollo comunitario.

Igualmente, conceptos vinculados directamente a la teorización del término de capital social son utilizados en el diseño de políticas públicas, como es el caso de las redes sociales. Se ha podido concretar cómo determinadas redes sociales facilitan a los sujetos que las integran la oportunidad de obtener mecanismos para concretar sus objetivos, tales como el desarrollo profesional, la obtención de recursos financieros o la obtención de empleo. Objetivos que, además, son comunes para lograr el bienestar no sólo del individuo particular sino de la sociedad a la que pertenecen, creándose así el beneficio mutuo entre individuos, y para la sociedad en su conjunto.

Esto es fácil de comprender pues las redes adquieren entidad propia cuando logran proveer de bienes y servicios tanto a las organizaciones que las configuran como a los sujetos inmersos en dichas asociaciones. Las personas, como actores principales de la conformación del movimiento asociativo, se benefician de las redes a las que cada una de las organizaciones pertenece. Los individuos fuera de éste entramado tendrán, siguiendo el razonamiento aristotélico, una mayor desigualdad y dificultad para la consecución de bienes y servicios básicos. La falta de participación en el capital social lleva a la situación de exclusión tanto desde la variable socio-emocional como económico-material.

De esta manera el capital social se considera un mecanismo básico de articulación de la sociedad, por cuanto la pertenencia a diferentes organizaciones, a través del asociacionismo, configura una red social en la que se pueden apreciar aspectos elementales para la estructuración social. Cuanto más densa sea esta red social, mayor grado de implicación existirá entre los miembros de la misma, ya sean personas como organizaciones, facilitando aún más el acceso a bienes y servicios, la acción tanto individual como colectiva y la creación de identidad y valores comunes. 
Por ello, el capital social se interpreta como un elemento de vertebración social al atender tanto a la creación de redes entre individuos, organizaciones e instituciones, como por facilitar el desarrollo de estructural sociales. La configuración de la sociedad se asienta, a su vez, en la implantación, por parte de esta acción colectiva, de valores e ideologías como moldeadores de la realidad social.

Como hemos visto, el capital social, además, es considerado como factor clave para el fortalecimiento democrático de cualquier país, pues contribuye, entre otros aspectos, al desarrollo institucional, fruto del cual se consigue una mayor y más rápida integración de los países en el desarrollo de un mundo globalizado. Volvemos a comprobar cómo los vínculos entre variables culturales y económicas parecen mayores de lo que el pensamiento neoclásico tomó en consideración. De esta forma las actividades sociales son entendidas como inversiones, en vez de consumidoras de recursos públicos. Como ejemplo se toma el caso de los países nórdicos, en concreto Suecia, heredera de la tradicional socialdemócrata escandinava, donde el Estado financia la creación de asociaciones juveniles, tanto culturales como deportivas, para luego perder su control en beneficio de la sociedad civil, fomentando así la participación política y ciudadana de sus jóvenes, lo que revierte en una mayor integración democrática y cívica de estos sujetos. Es decir, se fortalece el papel del capital social como estructurador de la sociedad, así como elemento imprescindible del análisis económico.

\section{Bibliografía}

Banco Mundial (1997a). Informe sobre el desarrollo Mundial, Departamento de publicaciones del Banco Mundial, Washington.

Banco Mundial (1997b). Social Capital: The Missing Link, en World Band, Expanding the Measure of Wealth: Indicators of Environmentally Sustainable Development, Environmentally Sustainable Development Studies and Mongraphs Series, $\mathrm{n}^{\circ} 17$, Washington.

Banco Mundial (1998). Las instituciones cuentan, Departamento de publicaciones del Banco Mundial, Washington.

Bourdieu, P. (1985). Social Space and the Genesis of Groups. Theory and Society, 14-6 November, p. 723-744, citado en Capital social: sus orígenes y aplicaciones en la sociología moderna, A. Portes (1999), en J. Carpio y I. Novacovsky (compiladores), De Igual a Igual. El desafio del Estado ante los nuevos problemas sociales, p. 248, Buenos Aires: Fondo de Cultura Económica.

Bourdieu, P. (1992). El sentido práctico, p.88 y 92, Madrid: Taurus. 
Coleman, J. S. (1988). Social Capital in the Creation of Human Capital, American Journal of Sociology, vol.94, suplemento, p. 95-120.

Coleman, J. S. (1990). Foundations of Social Theory, p. 301, 302, 307, 310 y 311, Harvard University Press, Cambridge, Massachusetts and London.

Durkheim, E. (1993). Escritos Selectos. Introducción y selección de Anthony Giddens, Buenos Aires: Nueva Visión.

Fukuyama, F. (1992). El fin de la historia y el último hombre, Barcelona: Editorial Planeta.

Fukuyama, F. (1995). Social Capital and the Global Economy, p. 89-103,Foreign Affairs, vol. 74, n ${ }^{\circ} 5$.

Granovetter, M. (1973). The Strength of Weak Ties, p. 1360-1380, American Journal of Sociology, vol.78, $\mathrm{n}^{\circ} 6$, traducción (2000) La fuerza de los vínculos débiles, Madrid: Política y Sociedad, nº33, 48

Hanifan, L. J. (1916). The rural school community center, Annals of the American Academy of Political and Social Science, n'67, pp.130-138.

Harriss, J. y De Renzio, P. (1997). An introductory Bibliographic Essay, en J. Harriss (ed.), Policy Arean: Missing link or Analytically Missing: The Concept of Social Capital, monográfico de Journal of International Development, vol.9, ${ }^{\circ} 7$.

Loury, G. (1997). A dynamyc theory of racial income differences, en Women, Minorities and Employment Discrimination, P. A Wallace, Lexington MA: Health.

Naciones Unidas (1999). Informe de desarrollo humano, Programa para el desarrollo, http:/hdr.undp.org/es/informes/mundial/idh1999/

Portes, A. (1999). Capital social: sus orígenes y aplicaciones en la sociología moderna en J. Carpio y I. Novacovsky, De Igual a Igual. El desafío del Estado ante los nuevos problemas sociales, p. 248, Buenos Aires: Fondo de Cultura Económica.

Putnam, R. (1993). Making Democracy Work: civic Traditions in modern Italy, p.167 y 171, Princeton University Press.

Putnam, R. (2000). Bowling Alone: The Collapse and the Revival of American Community, p. 136, New York: Simon and Schuster.

Putnam, R. (2003). Entrevista en la revista Muy Interesante, $\mathrm{n}^{\circ}$ 271, Madrid. 
Putnam, R. (2003). El declive del capital social: un estudio internacional sobre las sociedades y el sentido comunitario, Madrid: Galaxia Gutenberg.

Smith, A. (1776). An Inquiry into the Nature and Cause of the Wealth of Nations, Londres. Traducción C. Rodriguez (2010), La Riqueza de las Naciones, Libro V, capítulo III, p. 148, Madrid: Alianza Editorial.

Stiglitz, J. E. (2006). Cómo hacer que la globalización funcione, p. 255 y 264, Madrid: Taurus.

Stiglitz, J. E. (2009). El malestar en la globalización, p. 287, Madrid: Santillana Ediciones.

UNESCO (1996). Informe de la Comisión Mundial de Cultura y Desarrollo, p.14, París, septiembre.

Ward, B. (1973). Las instituciones y el análisis económico, en La estructura de la Ciencia Económica, S. R. Krupp, p. 252, Madrid: Aguilar.

Weber, M. (2003). La ética protestante y el espiritu del capitalismo, Méjico: Fondo de Cultura Económica. 